\title{
Research Article \\ Effects of Cinnamon (Cinnamomum cassia) Consumption on Serum Lipid Profiles in Albino Rats
}

\author{
Fahadah Naeef Alsoodeeri, ${ }^{1}$ Hissah Mohammed Alqabbani, ${ }^{2}$ \\ and Norah Mubarak Aldossari $\mathbb{i D}^{3}$ \\ ${ }^{1}$ Department of Home Economics, College of Home Economics, King Khalid University, Abha, Saudi Arabia \\ ${ }^{2}$ Department of Home Economics, College of Education-Dilam, Prince Sattam Bin Abdulaziz University, Al-Kharj, Saudi Arabia \\ ${ }^{3}$ Department of Home Economics, College of Education-Wadi Addawasir, Prince Sattam Bin Abdulaziz University, \\ Al-Kharj, Saudi Arabia
}

Correspondence should be addressed to Norah Mubarak Aldossari; nora525100@yahoo.com

Received 15 September 2019; Accepted 5 November 2019; Published 23 January 2020

Academic Editor: Gerhard M. Kostner

Copyright (c) 2020 Fahadah Naeef Alsoodeeri et al. This is an open access article distributed under the Creative Commons Attribution License, which permits unrestricted use, distribution, and reproduction in any medium, provided the original work is properly cited.

\begin{abstract}
Dyslipidemia is an important cause of cardiovascular diseases (CVDs), which are the most prevalent causes of morbidity and mortality. The purpose of this study was to assess the effects of cinnamon on body weight gain, food intake, and serum lipid profiles of albino rats. This study was conducted on 30 healthy male albino rats weighing approximately $130 \pm 5 \mathrm{~g}$. The study was divided into the following two experiments: experiment (1), wherein rats were fed a laboratory diet; and experiment (2), wherein rats were fed a high-fat diet. In experiment 1 , a total of 15 rats were divided into three groups. Group A $(n=5$, untreated control) was fed laboratory diet, Group B $(n=5)$ was fed laboratory diet and cinnamon powder $(2 \mathrm{~g} / \mathrm{kg}$ body weight), and Group C $(n=5)$ was fed laboratory diet and cinnamon powder ( $4 \mathrm{~g} / \mathrm{kg}$ body weight) for 30 days. In experiment (2), a total of 15 rats were similarly divided into three groups. Group D $(n=5$, treated control) was fed laboratory diet plus high-fat diet, Group $\mathrm{E}(n=5)$ was fed cinnamon powder ( $2 \mathrm{~g} / \mathrm{kg}$ body weight) mixed with laboratory diet plus high-fat diet, and Group F $(n=5)$ was fed cinnamon powder $(4 \mathrm{~g} / \mathrm{kg}$ body weight) mixed with laboratory diet plus high-fat diet daily for 30 days. An administration of $4 \mathrm{~g} / \mathrm{kg}$ body weight of cinnamon extract powder decreased the final weight by $4.4 \%$, body weight gains by $31.41 \%$, food intake by $1.7 \%$, and food efficiency ratio by $22.38 \%$ in hypercholesterolemic adult male rats as well as serum total cholesterol by $31.22 \%$, triglyceride by $24.05 \%$, and LDL-C by $43.49 \%$, with an increase in the levels of HDL-C by $30.16 \%$, furthermore, a significant decrease in serum total cholesterol, triglycerides, and LDL-C levels and increasing serum HDL-C on day 30 were observed $(P<0.001)$. This finding provides scientific evidence to substantiate the traditional use of cinnamon to treat hyperlipidemia.
\end{abstract}

\section{Introduction}

Dyslipidemia is an important cause of cardiovascular diseases (CVDs), which are the most prevalent reasons for morbidity and mortality. These diseases are characterized by elevated blood lipids, which include at least one of the following alterations in the lipid profile: increased serum levels of low-density lipoprotein cholesterol (LDL-C) and triglycerides, and/or decreased levels of high-density lipoprotein cholesterol (HDL-C) in systemic circulation. These factors are among the leading causes of CVDs [1-3]. Globally, CVDs resulted in 17.3 million human deaths $(32.1 \%)$ in 2015 , an increase from the 12.3 million deaths $(25.8 \%)$ reported in 1990 ; CVDs are respon- sible for over $31 \%$ of all deaths reported worldwide $[4,5]$. In developing countries, mortality caused by CVDs is expected to rise to 19 million by 2020 [6].

The organic material cinnamon, one of the most important and popular spices used daily by people worldwide without any side effects, is extracted from the inner bark of trees of the genus Cinnamomum of the family Lauraceae. It is represented by approximately 250 species widely found across Asia, Australia, and South America $[7,8]$. Cinnamomum cassia, called Chinese cassia or Chinese cinnamon is an evergreen tree originating in southern China, and widely cultivated there and elsewhere in southern and eastern Asia. It is one of the most important spices and medicinal materials in the world [9]. Cinnamon extract is 
a more concentrated source of flavor than ground cinnamon, similar to vanilla extract. Cinnamon primarily contains vital oils and other derivatives, such as cinnamaldehyde, cinnamic acid, and cinnamate, and these derivatives play vital roles in its natural antioxidant [10], anti-inflammatory [11], antidiabetic $[12,13]$, antimicrobial $[14,15]$, anticancer $[16,17]$, and cholesterol-lipid-lowering properties [12, 18, 19].

Previously, Kim et al. investigated the anti-diabetic effect of Cinnamomi cassiae extract at different dosages (50, 100, 150, and $200 \mathrm{mg} / \mathrm{kg}$ ) in a mouse $(\mathrm{C} 57 \mathrm{BI} / \mathrm{KsJ} \mathrm{db} / \mathrm{db})$ model of type II diabetes for six weeks. The administration of cinnamon to mice positively affected the lipid profile, whereby the serum HDL-C and triglyceride levels were reduced [20]. Another study reported that C. cassiae powder (15\%) decreased serum total cholesterol, triglycerides, and LDL-C in rats after 35 days [21]. Recently, a study also reported that $500 \mathrm{mg}$ of cinnamon water-extract used for two months by 137 men and women from Beijing and Dalian, China resulted in reduction of the total cholesterol and LDL-C levels [19]. However, the effect of cinnamon on blood lipids is still controversial and the mechanism by which cinnamon supplements influence the level of blood lipids needs further investigation. The present study aimed to assess the effects of cinnamon on body weight gain, food intake, food efficiency ratio, and serum lipid profile of albino rats.

\section{Materials and Methods}

This experimental study was conducted at the Department of Food Science and Nutrition, College of Food and Agriculture Sciences, King Saud University, Saudi Arabia from January 2017 to August 2017.

2.1. Sample, Diets, Chemicals, and Biochemical Analysis. Cinnamon bark (Cinnamomum cassia), cholesterol, and cholic acid were purchased from the local market in Riyadh, Saudi Arabia. Cinnamon extract was ground with a plant tissue grinder. Cinnamon bark $(1 \mathrm{~kg})$ was extracted twice with $640 \mathrm{ml}$ of water for $16 \mathrm{~h}$ at $90^{\circ} \mathrm{C}$ and filtered. The water extract was lyophilized in a drying oven at $60^{\circ} \mathrm{C}$, finely powdered with a mechanical mixer and then stored at room temperature until further use [20]. The finely lyophilized cinnamon was weighed $(1 \mathrm{~kg})$ and mixed with $1000 \mathrm{ml}$ of water. This extract was diluted weekly with water and orally administered to the rats at particular doses. The cinnamon powder was then fed at a daily dose of $2 \mathrm{~g} / \mathrm{kg}$ to the animals of treatment groups $\mathrm{B}$, $\mathrm{C}, \mathrm{E}$, and $\mathrm{F}$ for 30 days. These four groups also received daily doses of cinnamon extract ( $4 \mathrm{~g} / \mathrm{kg}$ body weight) for 30 days.

Total cholesterol, triglycerides, and HDL-C were purchased from Thermo Fisher (catalog number 981301 for triglycerides, 981812 for total cholesterol, and 981823 for HDL-C). Serum lipid profiles (total cholesterol, triglycerides, LDL-C, and HDLC) were determined by the enzymatic colorimetric (CHODPAP) method using an automated biochemistry analyzer (Konelab 20, Thermo Fisher Scientific, Helsinki, Finland). Low density lipoprotein cholesterol (LDL-C) was estimated using the Friedewald formula [22].

2.2. Animals. Thirty healthy adult male albino rats (Rattus norvegicus) weighing approximately $130 \pm 5 \mathrm{~g}$ were obtained from the animal rearing facility of the Zoology Department, College of Science, King Saud University, Saudi Arabia. Before the experiment, rats were fed water and laboratory diet ( $40 \mathrm{~g} /$ day) for 5 days and housed at $25 \pm 5^{\circ} \mathrm{C}$ under good ventilation. Ethical approval was obtained from the Ethics Committee of the College of Science Research Center of King Saud University, Riyadh, Saudi Arabia (8/25/256345).

2.3. Measurement of Growth Indicators. The body weight and food intake of the animals were recorded at the beginning of and during the experimental period.

2.3.1. Body Weight Gain (g). Weight gain for the entire 30day period was calculated as final weight-initial weight for each rat.

2.3.2. Food Intake (g). Food intake was calculated every day as total food consumption/duration for each rat, all unconsumed food and pellets were removed and replaced with new laboratory diet ( $40 \mathrm{~g} /$ day).

2.3.3. Food Efficiency Ratio. The food efficiency ratio was calculated as mean daily body weight gain $(\mathrm{g}) / \mathrm{mean}$ daily food intake (g) for each rat.

2.4. Experiment Design 1. Experiment 1 was conducted to demonstrate the effect of cinnamon on normal adult male albino rats. A total of 15 rats were divided into three groups of 5 rats each. Each cage contained one rat and was labeled carefully for identification of the different groups.

Group A (Untreated Control). The group A rats served as untreated controls or normal controls, each albino rat received laboratory diet ( $40 \mathrm{~g} /$ day) and water for 30 days.

Group B. Each rat received cinnamon powder $(2 \mathrm{~g} / \mathrm{kg}$ body weight) mixed with laboratory diet ( $40 \mathrm{~g} /$ day) and water for 30 days.

Group C. Each rat received cinnamon powder $(4 \mathrm{~g} / \mathrm{kg}$ body weight) mixed with laboratory diet ( $40 \mathrm{~g} /$ day) and water for 30 days.

Experiment Design 2. Experiment 2 was conducted to demonstrate the effects of cinnamon on hypercholesterolemic rats.

Group D (Treated Control). Each rat served as a treated control and was orally administered laboratory diet ( $40 \mathrm{~g} /$ day) plus $1 \%$ cholesterol with $0.25 \%$ cholic acid and water for 30 days.

Group E. Each rat orally received cinnamon powder ( $2 \mathrm{~g} / \mathrm{kg}$ body weight) mixed with laboratory diet ( $40 \mathrm{~g} /$ day) plus $1 \%$ cholesterol with $0.25 \%$ cholic acid and water for 30 days.

Group F. Each rat orally received cinnamon powder ( $4 \mathrm{~g} / \mathrm{kg}$ body weight) mixed with laboratory diet ( $40 \mathrm{~g} /$ day) plus $1 \%$ cholesterol with $0.25 \%$ cholic acid and water for 30 days. 
TABLE 1: Effects of cinnamon extract powder on body weight gain, food intake, food efficiency ratio, and serum lipid profiles of normal adult male rats.

\begin{tabular}{|c|c|c|c|c|c|c|c|}
\hline \multirow{3}{*}{ Parameters } & \multirow{3}{*}{$\begin{array}{l}\text { Group A } \\
\quad(n=5)\end{array}$} & \multirow{3}{*}{$\begin{array}{l}\text { Group B } \\
(n=5)\end{array}$} & \multirow{3}{*}{$\begin{array}{l}\text { Group C } \\
(n=5)\end{array}$} & \multicolumn{4}{|c|}{ Percentage reduction } \\
\hline & & & & \multicolumn{2}{|c|}{ Group B } & \multicolumn{2}{|c|}{ Group C } \\
\hline & & & & $\%$ & $P$ value & $\%$ & $P$ value \\
\hline Initial weight $(\mathrm{g})$ & $131.8 \pm 1.2$ & $130.12 \pm 2.3$ & $132.3 \pm 2.1$ & 1.3 & 0.62 & 0.33 & 0.56 \\
\hline Final weight (g) & $155.4 \pm 3$ & $150.4 \pm 3.6$ & $151.3 \pm 3.6$ & 3.2 & 0.35 & 2.59 & 0.12 \\
\hline Body weight gain (g) & $23.5 \pm 2.1$ & $20.2 \pm 1.4$ & $19.1 \pm 1.4$ & 13.9 & 0.29 & 19.00 & 0.32 \\
\hline Food intake $(\mathrm{g})$ & $27.8 \pm 6.6$ & $26.8 \pm 6.1$ & $26.6 \pm 5.3$ & 3.6 & 0.63 & 4.31 & 0.56 \\
\hline Food efficiency ratio & $0.84 \pm 0.31$ & $0.75 \pm 0.22$ & $0.71 \pm 0.26$ & 10.71 & 0.69 & 15.47 & 0.36 \\
\hline Serum total cholesterol $(\mathrm{mg} / \mathrm{dL})$ & $95.1 \pm 2.5$ & $91.2 \pm 1.5$ & $92.1 \pm 2.5$ & 2.1 & 0.45 & 4.14 & 0.12 \\
\hline Serum triglycerides $(\mathrm{mg} / \mathrm{dL})$ & $82.1 \pm 2.5$ & $79.1 \pm 2.5$ & $78.1 \pm 2.4$ & 3.7 & 0.36 & 4.87 & 0.25 \\
\hline Serum HDL-C (mg/dL) & $33.9 \pm 0.7$ & $35.2 \pm 0.8$ & $36.3 \pm 0.7$ & 3.8 & 0.24 & 7.08 & 0.35 \\
\hline Serum LDL-C (mg/dL) & $44.8 \pm 1.3$ & $40.2 \pm 1.8$ & $40.2 \pm 1.2$ & 10.4 & 0.36 & 10.28 & 0.35 \\
\hline
\end{tabular}

Data presented are mean \pm SD. $P$-value significant at $<0.05$.

2.5. Collection of Blood Specimens. At the end of 30 days, after a $12 \mathrm{~h}$ fasting period, all rats were euthanized using diethyl ether as the anesthetic agent. Blood samples were collected in test tubes and allowed to coagulate at room temperature. Each sample was transferred into a dry clean centrifuge tube and centrifuged at $3000 \mathrm{rpm}$ for $30 \mathrm{~min}$ for separating serum. The supernatant sera were quickly removed and stored at $-20^{\circ} \mathrm{C}$ for biochemical analysis of serum lipid profiles.

2.6. Statistical Analysis. SPSS version 16 (SPSS Inc. Chicago, IL, USA) was used for data acquisition and analysis. Data are presented as mean and standard deviation (SD) for continuous variables. Frequencies are presented as percentages (\%). Comparisons between groups were conducted using independent $t$-tests for continuous variables and Chi-square tests for categorical variables. To elucidate the effects of cinnamon on the biochemical parameters and body weight of the rats, paired $t$-tests were conducted. Statistical significance was set at $P<0.05$.

\section{Results}

3.1. Experiment 1. The effects of the cinnamon extract powder on body weight gain, food intake, food efficiency ratio, and serum lipid profiles of normal adult male rats are shown in Table 1 . On day 30 post-treatment, the cinnamon extract powder equivalent to $2 \mathrm{~g} / \mathrm{kg}$ body weight reduced the final weight by $3.22 \%$, body weight gains by $13.98 \%$, food intake by $3.59 \%$, and food efficiency ratio by $10.71 \%$. With respect to the lipid profile, serum total cholesterol was reduced by $2.10 \%$, triglycerides by $3.65 \%$, and LDL-C by $10.37 \%$. Although an increase was observed in HDL-C by $3.83 \%$, it was not a significant change. The administration of $4 \mathrm{~g} / \mathrm{kg}$ of body weight of cinnamon extract powder also reduced the final weight by $2.59 \%$, body weight gains by $19.00 \%$, food intake by $4.31 \%$, food efficiency ratio by $15.47 \%$, serum total cholesterol by $4.1 \%$, triglycerides by $4.87 \%$, and LDL-C levels by $10.28 \%$. The level of HDL-C was increased by $7.08 \%$. However, the changes in these parameters were non-significant.
TABLE 2: Weight, food intake and lipid profiles for adult, male rats on normal laboratory diet (Group A) compared to a high cholesterol diet (Group D).

\begin{tabular}{lccc}
\hline Parameters & $\begin{array}{c}\text { Group A } \\
(n=5)\end{array}$ & $\begin{array}{c}\text { Group D } \\
(n=5)\end{array}$ & $P$ value \\
\hline Initial weight $(\mathrm{g})$ & $131.8 \pm 1.2$ & $133.1 \pm 2.5$ & 0.28 \\
Final weight $(\mathrm{g})$ & $155.4 \pm 3$. & $159.3 \pm 4.3$ & $<0.001$ \\
Body weight gain $(\mathrm{g})$ & $23.5 \pm 2.1$ & $29.2 \pm 1.8$ & $<0.001$ \\
Food intake $(\mathrm{g})$ & $27.8 \pm 6.6$ & $39.2 \pm 8.5$ & $<0.001$ \\
Food efficiency ratio & $0.84 \pm 0.31$ & $0.67 \pm 0.21$ & 0.06 \\
Serum total cholesterol & $95.1 \pm 2.5$ & $138.3 \pm 5.9$ & $<0.001$ \\
(mg/dL) & & & \\
Serum triglycerides (mg/ & $82.1 \pm 2.5$ & $108.1 \pm 2.4$ & $<0.001$ \\
dL) & $33.9 \pm 0.7$ & $30.9 \pm 0.8$ & 0.07 \\
Serum HDL-C (mg/dL) & $44.8 \pm 1.3$ & $80.8 \pm 4.6$ & $<0.001$ \\
Serum LDL-C (mg/dL) & &
\end{tabular}

Data presented are mean \pm SD. $P$-value significant at $<0.05$.

3.2. Experiment 2. Comparison of weight, food intake, and lipid profile of adult, male rats fed normal laboratory diet (Group A) and high-cholesterol diet (Group D) is shown in Table 2. Final weight, body weight gain, and food intake values of the treated control (Group D) were significantly increased compared to those of the untreated control group (Group A) $(P<0.001)$. Serum total cholesterol, triglyceride, and LDL-C levels in the treated control (Group D) were also significantly increased than those of the untreated control (Group A) $(P<0.001)$.

The effects of cinnamon extract powder on body weight gain, food intake, food efficiency ratio, and serum lipid profiles of hypercholesterolemic adult male rats are shown in Table 3. Cinnamon extract powder equivalent to $2 \mathrm{~g} / \mathrm{kg}$ body weight decreased final weight by $3.11 \%$, body weight gains by $23.94 \%$, food intake by $3.31 \%$, and food efficiency ratio by $13.43 \%$. The lipid profile parameters also showed significant reduction; serum total cholesterol by $27.32 \%$, triglycerides by $16.65 \%$, and LDL-C by $49.06 \%$, with an increase in levels of HDL-C by $25.56 \%$ after 30 days of treatment. However, we did not observe a significant change. An administration of $4 \mathrm{~g} / \mathrm{kg}$ body 
TABLE 3: Effects of cinnamon extract powder on body weight gain, food intake, food efficiency, and serum lipid profiles in hypercholesterolemic adult male rats.

\begin{tabular}{|c|c|c|c|c|c|c|c|}
\hline \multirow{3}{*}{ Parameters } & \multirow{3}{*}{$\begin{array}{l}\text { Group D } \\
\quad(n=5)\end{array}$} & \multirow{3}{*}{$\begin{array}{l}\text { Group E } \\
(n=5)\end{array}$} & \multirow{3}{*}{$\begin{array}{l}\text { Group F } \\
(n=5)\end{array}$} & \multicolumn{4}{|c|}{ Percentage change } \\
\hline & & & & \multicolumn{2}{|c|}{ Group E } & \multicolumn{2}{|c|}{ Group F } \\
\hline & & & & $\%$ & $P$ value & $\%$ & $P$ value \\
\hline Initial weight $(\mathrm{g})$ & $133.1 \pm 2.5$ & $132.2 \pm 3.2$ & $132.3 \pm 3.2$ & 0.72 & 0.62 & 0.73 & 0.53 \\
\hline Final weight (g) & $159.3 \pm 4.3$ & $154.4 \pm 4.2$ & $152.3 \pm 5.3$ & 3.11 & 0.58 & 4.4 & 0.35 \\
\hline Body weight gain (g) & $29.2 \pm 1.8$ & $22.2 \pm 1.0$ & $20.0 \pm 2.1$ & 23.94 & 0.24 & 31.41 & $<0.001$ \\
\hline Food intake $(\mathrm{g})$ & $39.2 \pm 8.5$ & $37.93 \pm 6.1$ & $38.6 \pm 4.4$ & 3.31 & 0.65 & 1.75 & 0.35 \\
\hline Food efficiency ratio & $0.67 \pm 0.21$ & $0.58 \pm 0.17$ & $0.52 \pm 0.49$ & 13.43 & 0.45 & 22.38 & 0.35 \\
\hline Serum total cholesterol $(\mathrm{mg} / \mathrm{dL})$ & $138.3 \pm 5.9$ & $100.5 \pm 3.5$ & $95.1 \pm 4.4$ & 27.32 & 0.25 & 31.22 & $<0.001$ \\
\hline Serum triglycerides $(\mathrm{mg} / \mathrm{dL})$ & $108.1 \pm 2.4$ & $90.1 \pm 2.6$ & $82.1 \pm 3.5$ & 16.65 & 0.36 & 24.05 & $<0.001$ \\
\hline Serum HDL-C (mg/dL) & $30.9 \pm 0.8$ & $38.8 \pm 0.8$ & $40.2 \pm 0.6$ & 25.56 & 0.65 & 30.16 & $<0.001$ \\
\hline Serum LDL-C (mg/dL) & $80.8 \pm 4.6$ & $43.7 \pm 2.1$ & $48.5 \pm 3.1$ & 49.06 & 0.48 & 43.49 & $<0.001$ \\
\hline
\end{tabular}

Data presented are mean \pm SD. $P$-value significant at $<0.05$.

TABLE 4: Differences between Group E ( $2 \mathrm{~g} / \mathrm{kg}$ cinnamon extract powder) and Group F (4 g/kg cinnamon extract powder) in hypercholesterolemic adult male rats (E vs F).

\begin{tabular}{lccc}
\hline Parameters & $\begin{array}{c}\text { Group E } \\
(n=5)\end{array}$ & $\begin{array}{c}\text { Group F } \\
(n=5)\end{array}$ & $P$ value \\
\hline Initial weight $(\mathrm{g})$ & $132.2 \pm 3.2$ & $132.3 \pm 3.2$ & 0.53 \\
Final weight $(\mathrm{g})$ & $154.4 \pm 4.2$ & $152.3 \pm 5.3$ & 0.29 \\
Body weight gain $(\mathrm{g})$ & $22.2 \pm 1.0$ & $20.0 \pm 2.1$ & 0.42 \\
Food intake $(\mathrm{g})$ & $37.93 \pm 6.1$ & $38.6 \pm 4.4$ & 0.21 \\
Food efficiency ratio & $0.58 \pm 0.17$ & $0.52 \pm 0.49$ & 0.62 \\
Serum total cholesterol & $100.5 \pm 3.5$ & $95.1 \pm 4.4$ & $<0.001$ \\
(mg/dL) & & & \\
Serum triglycerides (mg/ & $90.1 \pm 2.6$ & $82.1 \pm 3.5$ & $<0.001$ \\
dL) & $38.8 \pm 0.8$ & $40.2 \pm 0.6$ & 0.24 \\
Serum HDL-C (mg/dL) & $43.7 \pm 2.1$ & $48.5 \pm 3.1$ & $<0.001$ \\
Serum LDL-C (mg/dL) &
\end{tabular}

Data presented are mean \pm SD. $P$-value significant at $<0.05$.

weight of cinnamon extract powder decreased the final weight by $4.4 \%$, body weight gain by $31.41 \%$, food intake by $1.7 \%$, and food efficiency ratio by $22.38 \%$. In addition, serum total cholesterol was reduced by $31.22 \%$, triglycerides by $24.05 \%$, and LDL-C by $43.49 \%$, with an increase in the levels of HDL-C by $30.16 \%$. Significant reductions were recorded only for body weight gain, serum total cholesterol, triglycerides, and LDL-C $(P<0.001)$.

The differences between Group E ( $2 \mathrm{~g} / \mathrm{kg}$ cinnamon extract powder) and Group F (4g/kg cinnamon extract powder) in hypercholesterolemic adult male rats are shown in Table 4. Serum total cholesterol and triglycerides in Group E were significantly higher than those in Group F, whereas LDL-C was significantly lower $(P<0.001)$. No other statistically significant differences were observed.

The comparison of effects of cinnamon extract powder on body weight gain, food intake, food efficiency, and serum lipid profile in normal and hypercholesterolemic adult male rats Group B vs Group E and Group C vs Group F is shown in Table 5. The final weight and food intake as well as serum total cholesterol, triglycerides, and LDL-C in Group B were significantly lower than those in Group E $(P<0.001)$. Similarly, food intake, serum total cholesterol, triglycerides, and LDL-C in Group C were significantly reduced compared to those in Group $\mathrm{F}(P<0.001)$. No other statistically significant differences were observed.

\section{Discussion}

Based on the results, a significant increase in the final weight, body weight gain, and food intake was observed (Table 2) $(P<0.001)$ after administration of the high-fat mixture $(1 \%$ cholesterol with $0.25 \%$ cholic acid) for 30 days in the treated control (Group D) compared to that of the untreated control (Group A). This was possibly caused by the accumulation of fat in the body. These findings are consistent with the results of a previous study which showed a rapid increase in the body weight of rats fed a high-fat diet over 8 weeks [23]. In contrast, another study did not support these results [24].

The serum total cholesterol, triglyceride, and LDL-C levels were also significantly increased after the 30-day administration of the high-fat mixture (Table 2) $(P<0.001)$. These findings were consistent with those of several previous studies, which showed that rats fed a diet rich in cholesterol had increased serum lipid profile parameters [21,25-27]. Cholic acid increases hyperlipidemia possibly through two mechanisms, an increase in cholesterol absorption and a concomitant suppression of cholesterol $7 \alpha$-hydroxylase activity that results in decreased cholesterol excretion. Cholic acid supplementation also enhances cholesterol absorption by its emulsifying property [28].

The bark of various cinnamon species is used worldwide as a spice in cooking. Cinnamon has been considered a safe flavoring agent in food for thousands of years, and there have been no reports of any side effects $[29,30]$. We observed a slight decrease in the final weight, body weight gain, food intake, as well as serum total cholesterol, triglycerides, and LDL-C in normal adult male rats treated with cinnamon extract powder (Group B and Group C) compared to those in the untreated control (Group A). However, these differences were not significant (Table 1). These observations were consistent with the results of previous studies [21,23,31]. 
TABLE 5: Comparison of effects of cinnamon extract powder on body weight gain, food intake, food efficiency, and serum lipid profiles in normal and hypercholesterolemic adult male rats Group (B vs E) and (C vs F).

\begin{tabular}{|c|c|c|c|c|c|c|}
\hline Parameters & $\begin{array}{c}\text { Group B } \\
(n=5)\end{array}$ & $\begin{array}{c}\text { Group E } \\
(n=5)\end{array}$ & $P$ value & $\begin{array}{c}\text { Group C } \\
(n=5)\end{array}$ & $\begin{array}{c}\text { Group F } \\
(n=5)\end{array}$ & $P$ value \\
\hline Initial weight $(\mathrm{g})$ & $130.12 \pm 2.3$ & $132.2 \pm 3.2$ & 0.62 & $132.3 \pm 2.1$ & $132.3 \pm 3.2$ & 0.98 \\
\hline Final weight $(\mathrm{g})$ & $150.4 \pm 3.6$ & $154.4 \pm 4.2$ & $<0.001$ & $151.3 \pm 3.6$ & $152.3 \pm 5.3$ & 0.48 \\
\hline Body weight gain (g) & $20.2 \pm 1.4$ & $22.2 \pm 1.0$ & 0.08 & $19.1 \pm 1.4$ & $20.0 \pm 2.1$ & 0.49 \\
\hline Food intake $(\mathrm{g})$ & $26.8 \pm 6.1$ & $37.93 \pm 6.1$ & $<0.001$ & $26.6 \pm 5.3$ & $38.6 \pm 4.4$ & $<0.001$ \\
\hline Food efficiency ratio & $0.75 \pm 0.22$ & $0.58 \pm 0.17$ & 0.08 & $0.71 \pm 0.26$ & $0.52 \pm 0.49$ & 0.62 \\
\hline Serum total cholesterol $(\mathrm{mg} / \mathrm{dL})$ & $91.2 \pm 1.5$ & $100.5 \pm 3.5$ & $<0.001$ & $92.1 \pm 2.5$ & $95.1 \pm 4.4$ & $<0.001$ \\
\hline Serum triglycerides (mg/dL) & $79.1 \pm 2.5$ & $90.1 \pm 2.6$ & $<0.001$ & $78.1 \pm 2.4$ & $82.1 \pm 3.5$ & $<0.001$ \\
\hline Serum HDL-C (mg/dL) & $35.2 \pm 0.8$ & $38.8 \pm 0.8$ & 0.24 & $36.3 \pm 0.7$ & $40.2 \pm 0.6$ & 0.06 \\
\hline Serum LDL-C (mg/dL) & $40.2 \pm 1.8$ & $43.7 \pm 2.1$ & $<0.001$ & $40.2 \pm 1.2$ & $48.5 \pm 3.1$ & $<0.001$ \\
\hline
\end{tabular}

Data presented are mean \pm SD. $P$-value significant at $<0.05$.

The most important finding of this study was that cinnamon extract powder at doses of $2 \mathrm{~g} / \mathrm{kg}$ body weight per day for 30 days slightly reduced body weight gain, serum total cholesterol, triglycerides, and LDL-C levels, whereas HDL-C was increased compared to those of the treated control (Group D) in hyperlipidemic adult male rats (Table 3). These results are consistent with previous studies reporting that cinnamon powder at $2 \mathrm{~g} / \mathrm{kg}$ body weight decreased the serum total lipids by $11.83 \%$, total cholesterol by $31.58 \%$, triglycerides by $33.50 \%$, and LDL-C by $63.40 \%$, whereas HDL-C was increased by $56.36 \%$ on day 60 post treatment [26]. Rahman et al. also reported that $15 \%$ cinnamon powder significantly decreased the serum total cholesterol by $12 \%$, triglycerides by $11 \%$, LDL-C by $14 \%$ in high-fat mixture-fed rats [21]. Similar findings were obtained in another study [32]. Our study showed that the administration of $4 \mathrm{~g} / \mathrm{kg}$ body weight of cinnamon extract powder significantly reduced the levels of the serum lipid profile (total cholesterol, triglycerides, and LDL-C) (Table 3) $(P<0.001)$. This is in accordance with a previous finding by Iqbal et al., who showed that administration of a high-cholesterol diet with cinnamon powder equivalent to $4 \mathrm{~g} / \mathrm{kg}$ body weight significantly decreased the serum total lipids, total cholesterol, triglycerides, and LDL-C in rats on day 60 post-treatment [26].

Cinnamon extract improves hyperlipidemia, possibly by playing a direct role in lipid metabolism by inhibiting hepatic $\beta$-hydroxy $\beta$-methylglutaryl-CoA (HMG-CoA) reductase activity, resulting in lower cholesterol production in the liver and suppression of lipid peroxidation [33]. Furthermore, increased lecithin cholesterol acyl transferase (LCAT) activity, which is essential for blood lipid regulation, can cause elevated HDL-C levels $[34,35]$. The decreased triglyceride levels may be caused by the lipolytic action of cinnamon. In addition, the inhibition of triglyceride synthesis may also be responsible for maintenance of a low level of triglycerides [36].

However, the present study has some limitations. Cinnamomum cassia extract is effective in preventing hyperlipidemia, the most important risk factor associated with high incidence of myocardial infarctions and CVDs. Therefore, future studies should focus on identifying the major components responsible for hyperlipidemia and also aim to elucidate its underlying mechanism. Further studies could also establish the effect of Cinnamomum cassia on hyperlipidemic patients.

\section{Conclusion}

In conclusion, the results of the present study revealed that cinnamon extract has a hypolipidemic effect on hypercholesterolemic albino rats at different doses. Daily administration of cinnamon extract equivalent to $4 \mathrm{~g} / \mathrm{kg}$ showed significant antihyperlipidemic effect in hypercholesterolemic albino rats by decreasing serum total cholesterol, triglyceride, and LDL-C levels and increasing serum HDL-C on day $30(P<0.001)$. The mechanisms underlying the hypolipidemic effect and its cellular mechanism of action need to be elucidated in future studies.

\section{Data Availability}

The data used to support the findings of this study are available from the corresponding author upon request.

\section{Conflicts of Interest}

The authors declare no conflicts of interest.

\section{Funding}

This work supported by King Khalid University, Saudi Arabia.

\section{Acknowledgments}

The authors would like to express their gratitude to King Khalid University, Saudi Arabia for providing administrative and technical support.

\section{References}

[1] C. D. Furberg, R. B. Goldberg, B. V. Howard, J. H. Stein, and J. L. Witztum, "Lipoprotein management in patients with cardiometabolic risk: consensus statement from the American Diabetes Association and the American College of Cardiology Foundation," Diabetes Care, vol. 31, no. 4, pp. 811-822, 2008. 
[2] R. Belski, "Fiber, protein, and lupin-enriched foods: role for improving cardiovascular health," Advances in food and nutrition research, pp. 147-215, 2012.

[3] Q.-Y. Xu, Y.-H. Liu, Q. Zhang et al., "Metabolomic analysis of simvastatin and fenofibrate intervention in high-lipid dietinduced hyperlipidemia rats," Acta Pharmacologica Sinica, vol. 35, no. 10, pp. 1265-1273, 2014.

[4] H. Wang, M. Naghavi, C. Allen et al., "Global, regional, and national life expectancy, all-cause mortality, and cause-specific mortality for 249 causes of death, 1980-2015: a systematic analysis for the Global Burden of Disease Study 2015," The Lancet, vol. 388, no. 10053, pp. 1459-1544, 2016.

[5] I. Abubakar, T. Tillmann, and A. Banerjee, "Global, regional, and national age-sex specific all-cause and cause-specific mortality for 240 causes of death, 1990-2013: a systematic analysis for the Global Burden of Disease Study 2013," The Lancet, vol. 385, no. 9963, pp. 117-171, 2015.

[6] C. J. Murray and A. D. Lopez, "Alternative visions of the future: projecting mortality and disability, 1990-2020," in The Global Burden of Disease, C. J. L. Murray and A. D. Lopez, Eds., Harvard University, Cambridge, MA, USA, 1996.

[7] P. Ranasinghe, S. Pigera, G. S. Premakumara, P. Galappaththy, G. R. Constantine, and P. Katulanda, "Medicinal properties of "true" cinnamon (Cinnamomum zeylanicum): a systematic review," BMC Complementary and Alternative Medicine, vol. 13, no. 1, p. 275, 2013.

[8] A. Sangal, "Role of cinnamon as beneficial antidiabetic food adjunct: a review," Advances in Applied Science Research, vol. 2, no. 4, pp. 440-450, 2011.

[9] S. Geng, Z. Cui, X. Huang, Y. Chen, D. Xu, and P. Xiong, "Variations in essential oil yield and composition during Cinnamomum cassia bark growth," Industrial Crops and Products, vol. 33, no. 1, pp. 248-252, 2011.

[10] S. Kumar, N. Vasudeva, and S. Sharma, "GC-MS analysis and screening of antidiabetic, antioxidant and hypolipidemic potential of Cinnamomum tamala oil in streptozotocin induced diabetes mellitus in rats," Cardiovascular Diabetology, vol. 11, no. 1, p. 95, 2012.

[11] L. K. Chao, K.-F. Hua, H.-Y. Hsu, S.-S. Cheng, J.-Y. Liu, and S.-T. Chang, "Study on the antiinflammatory activity of essential oil from leaves of Cinnamomum osmophloeum," Journal of Agricultural and Food Chemistry, vol. 53, no. 18, pp. 7274-7278, 2005.

[12] S. M. Blevins, M. J. Leyva, J. Brown, J. Wright, R. H. Scofield, and C. E. Aston, "Effect of cinnamon on glucose and lipid levels in non-insulin-dependent type 2 diabetes," Diabetes Care, vol. 30, no. 9, pp. 2236-2237, 2007.

[13] P. Crawford, "Effectiveness of cinnamon for lowering hemoglobin $\mathrm{A} 1 \mathrm{C}$ in patients with type 2 diabetes: a randomized, controlled trial," The Journal of the American Board of Family Medicine, vol. 22, no. 5, pp. 507-512, 2009.

[14] B. Shan, Y.-Z. Cai, J. D. Brooks, and H. Corke, "The in vitro antibacterial activity of dietary spice and medicinal herb extracts," International Journal of Food Microbiology, vol. 117, no. 1, pp. 112-119, 2007.

[15] N. Matan, H. Rimkeeree, A. Mawson, P. Chompreeda, V. Haruthaithanasan, and M. Parker, "Antimicrobial activity of cinnamon and clove oils under modified atmosphere conditions," International Journal of Food Microbiology, vol. 107, no. 2, pp. 180-185, 2006.
[16] J. Lu, K. Zhang, S. Nam, R. A. Anderson, R. Jove, and W. Wen, "Novel angiogenesis inhibitory activity in cinnamon extract blocks VEGFR2 kinase and downstream signaling," Carcinogenesis, vol. 31, no. 3, pp. 481-488, 2009.

[17] S. J. Koppikar, A. S. Choudhari, S. A. Suryavanshi, S. Kumari, S. Chattopadhyay, and R. Kaul-Ghanekar, "Aqueous cinnamon extract (ACE-c) from the bark of Cinnamomum cassia causes apoptosis in human cervical cancer cell line ( $\mathrm{SiHa}$ ) through loss of mitochondrial membrane potential," BMC Cancer, vol. 10, no. 1, p. 210, 2010.

[18] M. Ciftci, U. G. Simsek, A. Yuce, O. Yilmaz, and B. Dalkilic, "Effects of dietary antibiotic and cinnamon oil supplementation on antioxidant enzyme activities, cholesterol levels and fatty acid compositions of serum and meat in broiler chickens," Acta Veterinaria Brno, vol. 79, no. 1, pp. 33-40, 2010.

[19] R. A. Anderson, Z. Zhan, R. Luo et al., "Cinnamon extract lowers glucose, insulin and cholesterol in people with elevated serum glucose," Journal of Traditional and Complementary Medicine, vol. 6, no. 4, pp. 332-336, 2016.

[20] S. H. Kim, S. H. Hyun, and S. Y. Choung, "Anti-diabetic effect of cinnamon extract on blood glucose in $\mathrm{db} / \mathrm{db}$ mice," Journal of Ethnopharmacology, vol. 104, no. 1-2, pp. 119-123, 2006.

[21] S. Rahman, H. Begum, Z. Rahman, F. Ara, M. J. Iqbal, and A. K. M. Yousuf, "Effect of cinnamon (Cinnamomum cassia) as a lipid lowering agent on hypercholesterolemic rats," Journal of Enam Medical College, vol. 3, no. 2, pp. 94-98, 2013.

[22] W. T. Friedewald, R. I. Levy, and D. S. Fredrickson, "Estimation of the concentration of low-density lipoprotein cholesterol in plasma, without use of the preparative ultracentrifuge," Clinical Chemistry, vol. 18, no. 6, pp. 499-502, 1972.

[23] D. Haripriya and K. Vijayalakshmi, "The effect of cinnamaldehyde on high fat diet induced wistar rats-a preliminary study," Journal of Sports Medicine, vol. 5, no. 12, pp. 5398-5404, 2014.

[24] D. E. Andrich, Y. Ou, L. Melbouci et al., "Altered lipid metabolism impairs skeletal muscle force in young rats submitted to a shortterm high-fat diet," Frontiers in Physiology, vol. 9, no. 1327, 2018.

[25] I. Javed, N. Zia-Ur-Rahman, M. Z. Khan et al., "Antihyperlipidaemic efficacy of Trachyspermum ammi in albino rabbits," Acta Veterinaria Brno, vol. 78, no. 2, pp. 229-236, 2009.

[26] Z. Iqbal, T. Ashraf, A. A. Khan, R. Hussain, and M. Mudassar, "Antihyperlipidemic efficacy of cinnamon in albino rats," Asian Journal of Agriculture Biology, vol. 4, no. 1, pp. 8-16, 2016.

[27] D. Varsha, S. Shubhangi, P. Mangesh, and N. Naikwade, "Antihyperlipidemic activity of Cinnamomum tamala Nees. on high cholesterol diet induced hyperlipidemia," International Journal of PharmTech Research, vol. 2, no. 4, pp. 2517-2521, 2010.

[28] M. H. Moghadasian, "Experimental atherosclerosis: a historical overview," Life Sciences, vol. 70, no. 8, pp. 855-865, 2002.

[29] B. für Risikobewertung, "High daily intakes of cinnamon: health risk cannot be ruled out," BfR Health Assessment, vol. 44, , 2006.

[30] S. Balasubramanian, P. Roselin, K. Singh, J. Zachariah, and S. Saxena, "Postharvest processing and benefits of black pepper, coriander, cinnamon, fenugreek, and turmeric spices," Critical Reviews in Food Science and Nutrition, vol. 56, no. 10, pp. 1585-1607, 2016.

[31] R. Amin, M. Z. Islam, M. Sen, S. N. Eva, S. Jesmin, and S. Nahar, "Anti-obesity effect of mushroom (Ganoderma lucidum) on experimentally induced obese rats," Anwer Khan Modern Medical College Journal, vol. 3, no. 2, pp. 11-14, 2012. 
[32] S. N. A. El-Rahman, A. M. Abdel-Haleem, and H. M. A. Mudhaffar, "Anti-diabetic effect of cinnamon powder and aqueous extract on rats," International Journal of Food, Nutrition and Public Health, vol. 3, no. 2, p. 183, 2010.

[33] J. S. Lee, S. M. Jeon, E. M. Park et al., "Cinnamate supplementation enhances hepatic lipid metabolism and antioxidant defense systems in high cholesterol-fed rats," Journal of Medicinal Food, vol. 6, no. 3, pp. 183-91, 2003.

[34] P. Subash Babu, S. Prabuseenivasan, and S. Ignacimuthu, "Cinnamaldehyde-a potential antidiabetic agent," Phytomedicine: International Journal of Phytotherapy and Phytopharmacology, vol. 14, no. 1, pp. 15-22, 2007.

[35] U. K. Patil, S. Saraf, and V. Dixit, "Hypolipidemic activity of seeds of Cassia tora Linn," Journal of Ethnopharmacology, vol. 90, no. 2-3, pp. 249-252, 2004.

[36] S. Kannappan, T. Jayaraman, P. Rajasekar, M. Ravichandran, and C. Anuradha, "Cinnamon bark extract improves glucose metabolism and lipid profile in the fructose-fed rat," Singapore Medical Journal, vol. 47, no. 10, p. 858, 2006. 